\title{
Arrhythmias in Dilated Cardiomyopathy: Diagnosis and Treatment
}

\author{
Massimo Zecchin, Daniele Muser, Laura Vitali-Serdoz, \\ Alessandra Buiatti, and Tullio Morgera
}

\section{Abbreviations and Acronyms}
AAD
Antiarrhythmic drugs
AATAC
Ablation vs. Amiodarone for Treatment of Atrial Fibrillation in
Patients with Congestive Heart Failure and an Implanted ICD/
CRTD
ACC American College of Cardiology
$\mathrm{AF}$
Atrial fibrillation
AHA
American Heart Association
AIC
Arrhythmia-induced cardiomyopathy

M. Zecchin $(\varangle) \cdot$ T. Morgera

Cardiovascular Department, Azienda Sanitaria Universitaria Integrata, University of Trieste (ASUITS), Trieste, Italy

e-mail: massimo.zecchin@asuits.sanita.fvg

D. Muser

Cardiac Electrophysiology, Cardiovascular Medicine Division, Hospital of the University of Pennsylvania, Philadelphia, PA, USA

Cardiothoracic Department, University Hospital of Udine, Udine, Italy

e-mail: daniele.muser@asuiud.sanita.fvg.it

L. Vitali-Serdoz

Division of Electrophysiology, Department of Cardiology, Klinikum Coburg,

Coburg, Germany

e-mail: laura.vitali-serdoz@klinikum-fuerth.de
A. Buiatti
Cardiovascular Department, Azienda Sanitaria Universitaria Integrata, University of Trieste (ASUITS), Trieste, Italy
Klinik und Poliklinik für Innere Medizin I—Kardiologie, Klinikum rechts der Isar-
Technische Universität München, Munich, Germany
e-mail: buiatti@mytum.de 


$\begin{array}{ll}\text { ATP } & \text { Antitachycardia therapy } \\ \text { AV } & \text { Atrioventricular block } \\ \text { BBR } & \text { Bundle branch reentry } \\ \text { CA } & \text { Catheter ablation } \\ \text { CASTLE-AF } & \text { Catheter ablation vs. standard conventional treatment in patients } \\ & \text { with left ventricular dysfunction and atrial fibrillation } \\ \text { CMR } & \text { Cardiac magnetic resonance } \\ \text { DCM } & \text { Dilated cardiomyopathy } \\ \text { EAM } & \text { Electroanatomic mapping } \\ \text { ECG } & \text { Electrocardiogram } \\ \text { ES } & \text { Electrical storm } \\ \text { ESC } & \text { European Society of Cardiology } \\ \text { HF } & \text { Heart failure } \\ \text { HR } & \text { Hazard ratio } \\ \text { HRS } & \text { Heart Rhythm Society } \\ \text { ICD } & \text { Implantable cardioverter-defibrillator } \\ \text { LBBB } & \text { Left bundle branch block } \\ \text { LGE } & \text { Late gadolinium enhancement } \\ \text { LMNA } & \text { Lamin A/C } \\ \text { LVEF } & \text { Left ventricular ejection fraction } \\ \text { NS } & \text { Nonsustained } \\ \text { OR } & \text { Odds ratio } \\ \text { PJRT } & \text { Permanent junctional reciprocating tachycardia } \\ \text { RBBB } & \text { Right bundle branch block } \\ \text { RF } & \text { Radiofrequency } \\ \text { SCN5A } & \text { Sodium voltage-gated channel alpha subunit 5 } \\ \text { SCD } & \text { Sudden cardiac death } \\ \text { SR } & \text { Sinus rhythm } \\ \text { VA } & \text { Ventricular arrhythmias } \\ \text { VEB } & \text { Ventricular ectopic beats } \\ \text { VT } & \text { Ventricular tachycardia } \\ & \end{array}$

\subsection{Burden and Kinds of Arrhythmias in Dilated Cardiomyopathy: Risk Stratification of Sudden Death}

Patients with dilated cardiomyopathy (DCM) can develop a broad range of bradyrhythmias and tachyarrhythmias including sinus node dysfunction, various degrees of atrioventricular block, interventricular conduction delay, and atrial and ventricular arrhythmias.

Conduction system disease (sinus node dysfunction, various degrees of atrioventricular block (AV), interventricular conduction delay, and bundle branch block) can occur with all cardiomyopathies, particularly in some familial forms such as lamin A/C mutations (LMNA), mitochondrial diseases, storage disorders (Fabry disease), and infiltrative diseases (amyloidosis). 
The arrhythmogenic substrate can be explained by an "irritable focus" resulting from myocardial fibrosis, high catecholamine levels, or stretching of myocardial fibers. In addition, the disruption of the link between the sarcolemma, the cytoskeleton, and the sarcomere can lead to modifications of ion channel function [1].

As the majority of dysfunctional ion channels are localized in the sarcolemma, disruption of the sarcolemma-sarcomere link could cause ion channel dysfunction; conversely, it is possible that the function of an ion channel caused by a gene mutation is primarily disturbed, leading to dysfunction of cytoskeletal protein binding partners and mechanical impairment with "secondary" DCM.

For example, in patients with DCM and sodium voltage-gated channel alpha subunit 5 (SCN5A) mutations, arrhythmias can be particularly frequent, including supraventricular arrhythmias (86\%), sick sinus syndrome (33\%), atrial fibrillation (AF) (60\%), ventricular tachycardia (VT) (33\%), and conduction disease (60\%) [2]. Functional abnormalities in the sarcolemma, cytoskeleton, or sarcomere can occur secondarily to the SCN5A mutations, while desmosomal and other intercalated disk proteins could also play a role in the different phenotypes (arrhythmic and DCM) that result from SCN5A mutations.

\subsubsection{Bradyrhythmias and Conduction Abnormalities}

Conduction system diseases can occur with virtually all cardiomyopathies but is particularly prevalent in some familial forms of DCM such as the LMNA mutations and inflammatory, mitochondrial, storage, or infiltrative diseases [3]. Mutations of LMNA account for 6\% of patients with DCM and [4] account for 33\% of the DCMs with AV block [5]. In a large population with familial and sporadic DCM, conduction defects were present in $62 \%$ of patients with and only in $6 \%$ without LMNA mutations [6]. In these patients conduction abnormalities can occur even years before heart failure or left ventricular (LV) dysfunction, so the onset of AV conduction defects in middle age or earlier should prompt an evaluation for inflammatory or familial cardiomyopathy, and even in the presence of normal left ventricular function, a close follow-up is needed.

Left bundle branch block (LBBB) is present in 25-30\% of patients with DCM; right bundle branch block $(\mathrm{RBBB})$ is rare, accounting for less than $5 \%$ of patients [7, 8], while RBBB and AV block are the predominant features in sarcoidosis [9].

No clear data about the meaning of bradyrhythmias in patients with DCM have been reported, but LMNA defects, often present in these patients, are associated with a worse prognosis [6]. Some data suggest that an implantable cardiac defibrillator (ICD) should be considered in all patient candidates to pacemaker implantation even in the absence of left ventricular dysfunction or ventricular tachyarrhythmias [10].

The prognostic role of bundle branch blocks (particularly LBBB) is debated; patients with LBBB can have a higher risk of death from heart failure or heart transplantation [7], but its onset during follow-up, rather than its mere presence, seems to be more relevant for the risk stratification of all-cause mortality: Aleksova et al., analyzing 608 patients with DCM from our registry [8], observed that patients with 
baseline LBBB had a significantly higher mortality rate than those without LBBB at the univariate analysis, but after a multiple covariate adjustment, only new-onset LBBB was an independent predictor of all-cause mortality (HR 3.18, 95\% CI:1.905.31, $P<0.001)$ at multivariable analysis.

\subsubsection{Supraventricular Arrhythmias}

Supraventricular arrhythmias can occur in patients with DCM, but their presence should prompt investigation for familial LMNA cardiomyopathy (present in $73 \%$ of patients with these gene carriers and only in $36 \%$ of patients without this gene defect) [6].

AV nodal reentry and accessory pathway-related tachycardia are usually unrelated to the DCM, while incessant atrial tachycardia can be the cause rather than the consequence of left ventricular dysfunction; however, in these patients diffuse fibrosis or alterations in the structure or LV function can be present also in the long-term follow-up, suggesting that, even after a successful treatment of arrhythmias, recovery can be incomplete due to a late treatment or the coexistence of a structural heart disease.

$\mathrm{AF}$ is present in about $10-15 \%$ of patients with DCM [11].

\subsubsection{Ventricular Arrhythmias}

Ventricular ectopic beats (VEB) and nonsustained ventricular arrhythmias (nsVA) are observed in about $40 \%$ of patients with DCM and reflect a particular arrhythmogenic substrate involving rapid nonsustained VT (nsVT) and/or frequent VEB, the latter occurring in up to $30 \%$ of cases [12]. However, the prognostic role of these arrhythmias is not clear, and conflicting data have been published in the last 30 years. Some studies [13-16] suggested a worse prognosis and a higher risk of Sudden Cardiac Death (SCD) in patients with nsVA. In others [17], nonsustained VT were predictors of SCD at univariate, but not at multivariable analysis, or were not predictive of SCD, maybe in light of the high incidence of nsVT in patients with DCM.

It was proposed that only the association of VA with other risk factors, as low left ventricular ejection fraction (LVEF), could help to identify patients at higher risk. Differently from other experiences, we observed that nsVT are associated with a higher risk only in patients without severe LV dysfunction ( LVEF > 0.35) while in patients with LVEF $\leq 0.35$ they do not give any additional information [18].

In addition, we did not identify any specific characteristic VT that can be useful for the risk. However, an "arrhythmic pattern" at presentation, as defined by the presence of unexplained syncope, nsVT, $\geq 1000 \mathrm{VEB} / 24 \mathrm{~h}$, or $\geq 50$ ventricular couplets/24 h, was associated with a higher incidence of SCD, sustained VT, or ventricular fibrillation compared with other patients $(30.3 \%$ vs. $17.6 \%, P=0.022)$, independently from LVEF, with no difference in the total mortality [12]. 


\subsubsection{Mechanisms}

In heart failure, the mechanisms of atrial and ventricular tachyarrhythmias can be multiple.

According to old studies published decades ago, VEB and nonsustained VT in patients with DCM are initiated by a focal mechanism [19]. However, sustained VA are caused by reentry [20] in a significant amount of patients with DCM, as suggested also by the high rate and efficacy of antitachycardia therapy (ATP), unexpectedly similar to that found in patients with ischemic cardiomyopathy [21].

Bundle branch block reentry (BBR) VT is a form of sustained monomorphic VT that utilizes the conduction system as a reentry circuit, usually with anterograde propagation over the right bundle and retrograde conduction over the left bundle. Activation of the ventricles via the right bundle fibers produces VT that has a typical LBBB QRS morphology. More rarely, the reverse sequence of conduction can also occur, leading to an RBBB configuration. BBR VT are not uncommon in DCM. Rapid VT (>200 beats/min), often resulting in syncope or cardiac arrest, is the clinical presentation. Catheter ablation of the right bundle is highly effective in abolishing BBR VT, often (but not always) resulting in complete AV block (because of the preexistent LBBB, which sometimes is not complete). However, because of severe LV dysfunction, ICD and/or cardiac resynchronization therapy is required in most patients.

\subsubsection{Risk Stratification of Sudden Cardiac Death}

The assessment of SCD risk in patients with DCM has been a challenge for the last 30 years; nevertheless, both total mortality and SCD rate have been definitely reduced in the last three decades: [22] in the 1980s, SCD rate was up to $18 \%$ per year $[13,15]$, but it was only around $2-3 \%$ in patients medically evaluated in the early 2000 [17, 23]. According to the Trieste Cardiomyopathy Registry, including more than 1000 DCM patients with a mean follow-up of 10 years, the incidence of major cardiac events has fallen to less than $2 \%$ per year, while the incidence of SCD is less than $0.5 \%$ per year. This could have several explanations, including a better diagnostic definition, an earlier diagnosis, the widespread of beta-blockers and mineralocorticoid receptor antagonists (the only drugs significantly associated with a SCD reduction) and, finally, ICD and resynchronization therapy [24].

Because of the relatively low incidence of events, it is difficult to identify patients who could benefit more from ICD treatment and to demonstrate a significant mortality reduction in a not well-selected population. This could also explain why most trials evaluating patients with DCM failed to prove a statistically significant benefit of ICD even in the presence of SCD reduction. In addition, in some trials, patients with nonischemic cardiomyopathy (which is not always synonymous of DCM) of different etiologies and a non-negligible risk of non-arrhythmic death (due to pump failure or noncardiac events) were included [25]. 
Another important issue is the timing of risk stratification. Only $31 \%$ of the patients with LVEF $\leq 0.35$ and NYHA class II-III at first presentation still have ICD indications 6 months after medical therapy implementation [26]. According to current European guidelines, at least 3 months of optimal medical treatment is required before considering ICD implantation [27].

Despite hundreds of publications and several parameters analyzed, the severity of left ventricular dysfunction is still the major predictor of arrhythmic events, and current guidelines for ICD implantation in patients with DCM rely solely on LVEF value (together with the New York Heart Association functional class) [27, 28].

However, the odds ratio (OR) for LVEF is only 2.86 , with sensitivity and specificity of $71.1 \%$ and $50.5 \%$, respectively [29], suggesting that many patients with severe LV dysfunction do not benefit from ICD implantation but also that many patients with $\mathrm{LVEF} \geq 0.35$ can be at risk of SCD.

In addition to LVEF, many other parameters have been evaluated. According to the meta-analysis by Goldberger et al., four groups of parameters were considered: autonomic parameters (heart rate variability, baroreflex sensitivity, heart rate turbulence), functional parameters (as LVEF, left ventricular dimensions), depolarization abnormalities (fragmented QRS, intraventricular delay, signal-averaged ECG), repolarization abnormalities ( $\mathrm{T}$ wave alternans), and arrhythmic markers (spontaneous or induced arrhythmias) [29].

Taken individually, disturbances in autonomic function are poorly correlated with the risk of SCD, but also for other parameters, at best, the OR is generally between 2 and 4 . $\mathrm{T}$ wave alternans was the most sensitive predictor, while electrophysiologic study (EPS) was the most specific. EPS has been thought to have no utility in predicting the risk of SCD, despite the presence of scars, and reentry has been considered the most frequent mechanism of sustained VT in DCM. However, Gatzoulis et al. recently found that the incidence of VT terminated by the ICD during a median follow-up of 42 months was $73 \%$ in patients with induction of sustained VA at EPS, compared with $18 \%$ in non-inducible patients [12].

Despite its utility for selecting patients to receive an ICD has yet to be demonstrated, late gadolinium enhancement (LGE) by cardiac magnetic resonance (CMR) can detect the presence, site, and extension of cardiac fibrosis. Recently, two metaanalyses involving approximately 3000 patients each were published. According to the analysis performed by Disertori et al. [30] in a population with both ischemic and nonischemic cardiomyopathy, a composite arrhythmic end point (SCD, aborted SCD, VT/VF, and appropriate ICD therapy) was reached in $23.9 \%$ of patients with a positive LGE test (annualized event rate of $8.6 \%$ ) vs. $4.9 \%$ of patients with a negative LGE test (annualized event rate of $1.7 \% ; p<0.0001$ ). The OR was 5.62, without finding any difference between ischemic and nonischemic patients. In the subgroup of patients with LVEF $\leq 0.30$, the OR for the arrhythmic events increased to 9.56 .

The CMR Guide (Cardiac Magnetic Resonance Guided Management of MildModerate Left Ventricular Systolic Dysfunction) trial, which is currently randomizing ischemic and nonischemic patients with LVEF 36-50\% and presence of LGE to either ICD or an implantable loop recorder, will help to identify the role of CMR for selection of candidates to ICD but is estimated to be completed in December 2020 [31]. 
Another promising tool for the risk stratification, at least in some subgroups of patients, is the genetic analysis. Some genetic defects have been associated both with LV dysfunction and high risk of SCD. In most cases, these defects can be suspected through some "red flags" as conduction defects or supraventricular arrhythmias sometimes preceding the occurrence of $\mathrm{LV}$ dysfunction $[6,32]$ or alteration in the ion channel gene SCN5A [2]. When associated to other risk factors as nsVT, LVEF $<0.45$, non-missense mutation, and male sex, LMNA defects even in the absence of severe LV dysfunction represent a IIa recommendation to ICD implant according to both European and American guidelines [27, 28, 33]. In addition, in muscular dystrophies involving LMNA defects, an ICD is suggested as a IIb recommendation in the presence of conduction abnormalities and need of pacemaker implantation [27].

\subsubsection{Role of Supraventricular and Ventricular Arrhythmias in Pathogenesis of DCM}

\subsubsection{Definition and Pathophysiology}

Arrhythmias can initiate or aggravate acute heart failure (HF) in patients with preexisting heart disease. The arrhythmia-induced cardiomyopathy (AIC), known also as tachycardia-induced cardiomyopathy, is an important and potentially reversible cause of $\mathrm{HF}$ and DCM.

In 1949, Philips and Levine published the first description of HF induced by AF in patients without structural heart disease [34]. In the last decades, many reports underlined the role of arrhythmias in inducing HF or a DCM with a recovery of LV function after restoration of sinus rhythm or an adequate rate control.

Currently the AIC is defined on the basis of clinical criteria:

- Sustained heart rate $>100 / \mathrm{min}$

- Exclusion of other causes of HF

- Recovery (partial or complete) of LV function after achieving arrhythmia control (i.e., restoration of sinus rhythm or rate control)

Two forms of AIC can be identified: in the first form, "arrhythmia-induced" cardiomyopathy, the arrhythmia is the only identifiable cause of ventricular dysfunction, and in the second form, "arrhythmia-mediated," the arrhythmias aggravate ventricular dysfunction or worsens HF in subjects with underlying heart disease [35]. In patients with recent-onset HF and concomitant arrhythmias, a small LV end-diastolic diameter and mass index could indicate an AIC instead of a true DCM.

In animal models, the ventricular rapid pacing model demonstrated a more rapid reduction in LV function compared to the atrial pacing model, suggesting that myocardial electrical dyssynchrony plays an additional role accelerating the LV dysfunction [36].

In patients with AIC, the temporal relationship between occurrence of arrhythmias and development of LV remodeling, dysfunction and HF are not predictable. It 
is multifactorial, and there is no specific cutoff in heart rate determining a higher risk of developing AIC.

\subsubsection{Specific Clinical Pictures}

In adults, $\mathrm{AF}$ is the most common cause of AIC and is a concomitant arrhythmia in 10 up to $50 \%$ of patients in different cohort with HF [37]. Many mechanisms have been suggested as triggers for AIC during AF: loss of atrial contraction with concomitant irregular rhythm, resting tachycardia and inadequate exercise response affecting diastolic filling, and increasing left-sided filling pressure eventually leading to functional mitral regurgitation and mechano-electrical changes in the left atrium with a perpetuating cycle. The therapeutic options and strategies in patients with $\mathrm{AF}$ vary from a rate control (drugs or $\mathrm{AV}$-node ablation with biventricular pacing) to a rhythm control strategy (amiodarone and cardioversion or ablation).

In adults a persistent atrial flutter can play a significant role in patients with suspected AIC, because rate control is more difficult to achieve, given less concealed AV-node conduction. In this subgroup of patients, a catheter ablation is the therapy of first choice.

Less often, a persistent supraventricular tachycardia can induce an AIC, and also in this subset, whenever possible, a catheter ablation can normalize LV function.

Another important subset of AIC includes patients with idiopathic VT or frequent VEB; also in this subset, many different mechanisms have been postulated as ventricular dyssynchrony (in particular in VEB arising from right or left ventricular outflow tract with LBBB morphology), abnormal ventricular filling, and modification of $\mathrm{Ca}^{++}$handling. Moreover, some clinical characteristics have been identified in patients at high risk for AIC development: a high VEB burden ( $>24 \%$ or $>26 \%$ per day is cutoff strongly related to AIC with recovery after VEB ablation) $[38,39]$, interpolated VEB, retrograde $\mathrm{P}$ waves, male sex, asymptomatic VEB, QRS duration, and LBBB morphology.

In children, supraventricular arrhythmias are the main trigger for AIC, in particular atrial ectopic tachycardia and permanent junctional reciprocating tachycardia (PJRT). Atrial tachycardias arising from foci near the sinus node are more difficult to identify, usually appearing in children without structural heart disease. The clinical course of PJRT is often incessant with an unlikely spontaneous resolution and a higher risk of AIC; also in this setting, the catheter ablation is the treatment of first choice. In children, ventricular arrhythmias are rarely identifiable as the cause of HF.

\subsubsection{Management of Atrial Arrhythmias in Dilated Cardiomyopathy and Heart Failure}

Congestive $\mathrm{HF}$ and AF often coexist and adversely affect each other with respect to management and prognosis. No specific data on patients with DCM exist. Generally $\mathrm{HF}$ predisposes to AF promoting atrial electrical and structural change, whereas conversely, AF is implicated in the development and/or exacerbation of LV 
dysfunction as discussed. AF has been demonstrated to increase the mortality risk 1.5- to 2-fold in both sexes and across a wide range of ages. The risk of patients with $\mathrm{HF}$ developing AF is 1.6-fold in males and 2.7-fold in females, and the prevalence of AF increases with HF severity, ranging from $5 \%$ in functional class I patients to $\approx 50 \%$ in class IV patients [40]. It is intuitive that maintenance of normal sinus rhythm (SR) should improve functional status and possibly reduce mortality in this population. Nevertheless, large randomized trials failed to demonstrate any significant mortality benefit of a pharmacologically based rhythm control strategy, even in patients with LV dysfunction when compared to a rate control strategy [41-43]. In-depth analysis of these trials, indeed, demonstrated that the use of antiarrhythmic drug therapy to restore SR was associated with a $49 \%$ increase in mortality rate. Therefore, pursuing SR by non-pharmacologic means can be justified, considering also that several studies have demonstrated the superiority of catheter ablation over medical therapy $[44,45]$. Catheter ablation has demonstrated its superiority also compared to $\mathrm{AV}$-node ablation and biventricular pacing and is associated with the reduction of inappropriate and appropriate ICD therapies and with improvement in LVEF in patients with DCM [46]. The multicenter randomized AATAC (Ablation vs. Amiodarone for Treatment of Atrial Fibrillation in Patients with Congestive Heart Failure and an Implanted ICD/CRTD) trial [40] first showed a mortality benefit of catheter ablation vs. amiodarone, albeit in a combined secondary end point. In the CASTLE-AF trial [47], catheter ablation reduced death or hospitalization for heart failure in patients with congestive HF and AF compared with those assigned to medical therapy. Freedom from AF was strongly associated with stroke-free survival.

Cure of AF does not necessary imply its complete elimination. A significant reduction in the amount of time in $\mathrm{AF}$ after catheter ablation may be sufficient for achieving clinical benefit in patients with congestive HF. Although available data suggest that the safety and efficacy of catheter ablation are very similar in patients with $\mathrm{HF}$ and in those with normal hearts [48], success rate and long-term outcomes are expected to be influenced by patient complexity and concomitant comorbidities. It is well known that HF is an independent predictor of recurrent arrhythmia after catheter ablation; however, other covariates (such as age, sex, diabetes mellitus, and hypertension) have shown an association with ablation outcome. Additional imaging-based variables to predict efficacy and risk of ablation (as left atrial strain by speckle-tracking echocardiography and CMR for left atrial fibrosis size) are currently under investigation.

\subsubsection{Management of Ventricular Arrhythmias in Dilated Cardiomyopathy}

The life expectancy of patients affected by DCM is progressively growing. As a consequence, recurrent VT and electrical storm (ES) represent an emerging problem mainly in patients with severely depressed LVEF in whom frequent ICD 
shocks have been associated with poor quality of life, repeated hospitalizations, and increased mortality. In this setting, catheter ablation (CA) has demonstrated to be superior to antiarrhythmic drugs (AAD) in reducing VT recurrences and ICD shocks even if a mortality benefit has never been convincingly proven [49, 50]. The management of VT in this setting is challenging because of the complexity of the substrate and the underlying HF. Outcomes after CA are generally poorer compared to those of post-infarct VT. However, the evolution of electroanatomic mapping (EAM) systems together with the integration of noninvasive imaging modalities has significantly improved ablation strategies and long-term outcomes.

\subsubsection{Antiarrhythmic Drug Therapy of Ventricular Arrhythmias}

Therapy with AADs is often used to prevent long-term recurrences. In a recent meta-analysis of randomized controlled trials, a 1.5-fold reduction of VAs leading to appropriate ICD shocks has been noted with AADs compared to control medical therapy in patients with structural heart disease [49]. However, there is a substantial lack of data on efficacy and safety of AADs in patients with DCM. In such population, the choice of a specific drug should always take into account a potential negative inotropic effect with the associated possibility of worsening of the hemodynamic status along with proarrhythmic effects (Table 10.1). Amiodarone is usually the drug of choice as its efficacy has been demonstrated in randomized controlled trials with an overall threefold reduction of the risk of recurrent VT compared to beta-blockers. Unfortunately, the use of amiodarone is burdened by a high prevalence of organ toxicity (i.e., thyroid disorders, hepatitis, pulmonary fibrosis). Furthermore, the long-term use of amiodarone has been associated with an increased risk of death $[49,51,52]$. Another commonly used class III AAD is sotalol. Albeit its use seems to be safe in patients with structural heart disease and $\mathrm{HF}$, it has failed to demonstrate its superiority to other $\beta$-blockers in preventing recurrent ICD shocks [53-55]. Class I AADs should usually be avoided due to their significant negative inotropic effect and their potential proarrhythmic effect. Specifically, class IC drugs are contraindicated having been demonstrated to increase mortality in patients with structural heart disease [56]. Other class I AADs like mexiletine or procainamide may be used in adjunction to class III AADs or whether class III AADs cannot be administered. Adjuvant therapy with mexiletine has shown to reduce appropriate ICD therapies in case of amiodarone inefficacy [57]. However, it can worsen hemodynamic status in patients with severely reduced LVEF, and therefore its administration should be considered with caution. Procainamide is currently available only as an intravenous formulation in most countries, and there is some evidence suggesting high efficacy for acute termination of hemodynamically stable monomorphic VT even if it is generally avoided due to a significant risk of severe hypotension. No data concerning long-term oral administration are currently available. 
Table 10.1 Antiarrhythmic medications for acute and long-term treatment of ventricular tachycardia in patients with structural heart disease

\begin{tabular}{|c|c|c|c|c|}
\hline & & $\begin{array}{l}\text { Acute } \\
\text { management }\end{array}$ & $\begin{array}{l}\text { Long-term } \\
\text { treatment }\end{array}$ & $\begin{array}{l}\text { Desired plasma } \\
\text { concentration }\end{array}$ \\
\hline \multirow[t]{3}{*}{$\beta$-blockers } & Propranolol & $\begin{array}{l}\text { Bolus: } 0.15 \mathrm{mg} / \mathrm{kg} \\
\text { IV over } 10 \mathrm{~min}\end{array}$ & $\begin{array}{l}10-40 \mathrm{mg} \text { orally } \\
\text { three to four } \\
\text { times a day }\end{array}$ & NA \\
\hline & Metoprolol & $\begin{array}{l}\text { Bolus: } 2-5 \mathrm{mg} \text { IV } \\
\text { every } 5 \text { min up to } \\
\text { three doses in } \\
15 \mathrm{~min}\end{array}$ & $\begin{array}{l}25 \mathrm{mg} \text { orally } \\
\text { twice a day up to } \\
200 \mathrm{mg} \text { a day }\end{array}$ & NA \\
\hline & Esmolol & $\begin{array}{l}\text { Bolus: } 300- \\
500 \mathrm{mg} / \mathrm{kg} \text { IV for } \\
1 \mathrm{~min} \\
\text { Infusion: } \\
25-50 \mathrm{mg} / \mathrm{kg} / \mathrm{min} \\
\text { up to a maximum } \\
\text { dose of } 250 \mathrm{mg} / \\
\mathrm{kg} / \mathrm{min} \text { (titration } \\
\text { every } 5-10 \mathrm{~min} \text { ) }\end{array}$ & $\begin{array}{l}\text { Not } \\
\text { recommended }\end{array}$ & NA \\
\hline \multirow[t]{2}{*}{$\begin{array}{l}\text { Class III } \\
\text { agents }\end{array}$} & Amiodarone & $\begin{array}{l}\text { Bolus: } 150 \mathrm{mg} \text { IV } \\
\text { over } 10 \mathrm{~min} \text {, up to } \\
\text { total } 2.2 \mathrm{~g} \text { in } 24 \mathrm{~h} \\
\text { Infusion: } 1 \mathrm{mg} / \\
\text { min for } 6 \mathrm{~h} \text { and } \\
\text { then } 0.5 \mathrm{mg} / \mathrm{min} \\
\text { for } 18 \mathrm{~h}\end{array}$ & $\begin{array}{l}\text { Oral load: } \\
800 \text { mg orally } \\
\text { twice a day until } \\
10 \mathrm{~g} \text { total } \\
\text { Maintenance } \\
\text { dose: } 200- \\
400 \text { mg orally } \\
\text { daily }\end{array}$ & $\begin{array}{l}1.0-2.5 \mu \mathrm{g} / \mathrm{mL} \\
\text { No efficacy proven for } \\
\text { plasma concentrations } \\
<0.5 \mu \mathrm{g} / \mathrm{mL} \\
\text { Serious toxicity risk for } \\
\text { plasma concentrations } \\
>2.5 \mu \mathrm{g} / \mathrm{mL}\end{array}$ \\
\hline & Sotalol & Not recommended & $\begin{array}{l}80 \mathrm{mg} \text { orally } \\
\text { twice a day, up to } \\
160 \mathrm{mg} \text { twice a } \\
\text { day (serious side } \\
\text { effects }>320 \mathrm{mg} \text { / } \\
\text { day) }\end{array}$ & $\begin{array}{l}1-3 \mu \mathrm{g} / \mathrm{mL} \text { (not of great } \\
\text { value, usually } \\
\text { monitored by QT } \\
\text { prolongation with } \\
\text { indication to reduction/ } \\
\text { discontinuation if } \\
\text { prolongation }>15-20 \% \text { ) }\end{array}$ \\
\hline \multirow[t]{3}{*}{$\begin{array}{l}\text { Class I } \\
\text { agents }\end{array}$} & Procainamide & $\begin{array}{l}\text { Bolus: } 10 \mathrm{mg} / \mathrm{kg} \\
\text { IV over } 20 \mathrm{~min} \\
\text { Infusion: up to } \\
2-3 \mathrm{~g} / 24 \mathrm{~h}\end{array}$ & $\begin{array}{l}3-6 \text { g orally daily } \\
\text { fractionated in } \\
\geq 3 \\
\text { administrations }\end{array}$ & $4-12 \mu \mathrm{g} / \mathrm{mL}$ \\
\hline & Lidocaine & $\begin{array}{l}\text { Bolus: } 1.0- \\
1.5 \mathrm{mg} / \mathrm{kg} \mathrm{IV}, \\
\text { repeat dose of } \\
0.5-0.75 \mathrm{mg} / \mathrm{kg} \\
\text { IV up to a total } \\
\text { dose of } 3 \mathrm{mg} / \mathrm{kg} \\
\text { Infusion: } 20 \mu \mathrm{g} / \\
\mathrm{kg} / \mathrm{min} \text { IV }\end{array}$ & $\begin{array}{l}\text { Not } \\
\text { recommended }\end{array}$ & $2-6 \mu \mathrm{g} / \mathrm{mL}$ \\
\hline & Mexiletine & Not recommended & $\begin{array}{l}200 \mathrm{mg} \text { orally } \\
\text { three times a day, } \\
\text { up to } 400 \mathrm{mg} \\
\text { orally three times } \\
\text { a day }\end{array}$ & $0.6-1.7 \mu \mathrm{g} / \mathrm{mL}$ \\
\hline
\end{tabular}




\subsubsection{Catheter Ablation of Ventricular Arrhythmias}

Current American Heart Association/American College of Cardiology/Heart Rhythm Society guidelines recommend CA in patients with sustained monomorphic VT refractory to AAD therapy, including patients with ES not due to a transient or reversible cause [28]. Radiofrequency CA has proven to be highly effective in controlling VT compared to AADs. However, a clear mortality benefit related to CA has never been reproduced [50, 58-60]. Outcomes after CA of VT in the setting of DCM are heterogeneous and generally poorer compared to ischemic cardiomyopathy (Table 10.2). Technically, comprehensive substrate-based ablation approaches

Table 10.2 Principal studies assessing the role of VT ablation in dilated cardiomyopathy

\begin{tabular}{|c|c|c|c|c|c|c|c|}
\hline Study & $\begin{array}{l}\text { Number } \\
\text { of } \\
\text { patients }\end{array}$ & Age & $\begin{array}{l}\text { Baseline } \\
\text { LVEF } \\
(\%)\end{array}$ & $\begin{array}{l}\text { Epicardial } \\
\text { procedures } \\
(\%)\end{array}$ & $\begin{array}{l}\text { Amiodarone at } \\
\text { time of } \\
\text { procedure }(\%)\end{array}$ & $\begin{array}{l}\text { VT } \\
\text { recurrence, } \\
\%\end{array}$ & $\begin{array}{l}\text { Follow-up, } \\
\text { months }\end{array}$ \\
\hline $\begin{array}{l}\text { Hsia et al. } \\
2003 \text { [61] }\end{array}$ & 19 & $61 \pm 16$ & $34 \pm 11$ & 0 & 63 & 58 & $22 \pm 12$ \\
\hline $\begin{array}{l}\text { Soejima } \\
\text { et al. } \\
2004 \text { [20] }\end{array}$ & 28 & $54 \pm 14$ & $30 \pm 11$ & 29 & 43 & 36 & $9 \pm 9$ \\
\hline $\begin{array}{l}\text { Cano et al. } \\
2009 \text { [62] }\end{array}$ & 22 & $56 \pm 13$ & $30 \pm 13$ & 100 & 59 & 29 & $18 \pm 7$ \\
\hline $\begin{array}{l}\text { Nakahara } \\
\text { et al. } \\
2010 \text { [63] }\end{array}$ & 16 & $59 \pm 11$ & $27 \pm 12$ & 75 & 88 & 50 & $15 \pm 13$ \\
\hline $\begin{array}{l}\text { Schmidt } \\
\text { et al. } \\
2010[64]\end{array}$ & 16 & $57 \pm 11$ & $32 \pm 8$ & 94 & 69 & 47 & 12 (median) \\
\hline $\begin{array}{l}\text { Arya et al. } \\
2010 \text { [65] }\end{array}$ & 13 & $57 \pm 18$ & $33 \pm 9$ & 24 & - & 38 & 23 (median) \\
\hline $\begin{array}{l}\text { Haqqani } \\
\text { et al. } \\
2011 \text { [66] }\end{array}$ & 31 & $59 \pm 12$ & $30 \pm 14$ & 45 & 74 & 32 & $20 \pm 28$ \\
\hline $\begin{array}{l}\text { Piers et al. } \\
2013 \text { [67] }\end{array}$ & 45 & $60 \pm 16$ & $44 \pm 14$ & 64 & 42 & 53 & 24 (median) \\
\hline $\begin{array}{l}\text { Dinov et al. } \\
2014 \text { [68] }\end{array}$ & 63 & $59 \pm 13$ & $34 \pm 11$ & 30 & 33 & 59 & 12 \\
\hline $\begin{array}{l}\text { Oloriz et al. } \\
2014 \text { [69] }\end{array}$ & 87 & - & - & 74 & - & 51 & 18 (median) \\
\hline $\begin{array}{l}\text { Dinov et al. } \\
2015 \text { [70] }\end{array}$ & 102 & $59 \pm 15$ & $33 \pm 12$ & 28 & - & 56 & 24 \\
\hline $\begin{array}{l}\text { Tung et al. } \\
2015 \text { [59] }\end{array}$ & 966 & - & - & - & - & 32 & 12 \\
\hline $\begin{array}{l}\text { Yu et al. } \\
2015 \text { [71] }\end{array}$ & 73 & - & - & - & - & 60 & 6 \\
\hline $\begin{array}{l}\text { Muser } \\
\text { et al. } \\
2016 \text { [58] }\end{array}$ & 282 & $59 \pm 15$ & $36 \pm 13$ & 38 & 59 & 31 & 48 (median) \\
\hline
\end{tabular}


are related to better outcomes with long-term recurrence rates as low as $30 \%$ in experienced centers [58, 72].

Patients with advanced HF or ES are a high-risk group in which recurrent VT may simply represent a marker of worsening HF status, with limited possibility for achieving long-lasting arrhythmia control. In this setting, even if not able to directly improve survival, CA can still result in improved quality of life by reducing the number of ICD therapies and the need for AADs. In a large series of 193 patients, acute hemodynamic decompensation (AHD) occurred in $11 \%$ of subjects and was significantly related to increased mortality at follow-up (50\% mortality after a mean follow-up of 21 months vs. 11\%) [73]. In the same study, logistic regression analysis identified eight predictors of AHD which formed the PAINESD risk score, namely, chronic obstructive pulmonary disease (five points), age $>60$ years (three points), general anesthesia (four points), ischemic cardiomyopathy (six points), NYHA functional class III or IV (six points), ejection fraction $<25 \%$ (three points), presentation with VT storm (five points), and diabetes mellitus (three points) (Fig. 10.1) [73]. The predictive value of this score in identifying patients at high risk of adverse procedural outcomes has been subsequently validated in independent studies and, more recently, in a large international multicenter VT ablation registry [74]. It has been recently reported how patients undergoing VT ablation and considered at high risk on the basis of PAINESD score (PAINESD $\geq 15$ ) showed a substantial mortality benefit if treated with preemptive mechanical hemodynamic support (MHS) highlighting its potential role as bedside tool to select patients who may

\begin{tabular}{|l|l|}
\hline \multicolumn{1}{|c|}{ PAINESD RISK SCORE } & SCORE \\
\hline VARIABLE & 5 \\
\hline Pulmonary disease [chronic obstructive] - COPD & $\mathbf{3}$ \\
\hline Age $>60$ years & 4 \\
\hline Anesthesia [general] & 6 \\
\hline Ischemic cardiomyopathy & 6 \\
\hline NYHA class III or IV & $\mathbf{3}$ \\
\hline Ejection fraction $<25 \%$ & $\mathbf{5}$ \\
\hline Storm [VT] & $\mathbf{3}$ \\
\hline Diabetes mellitus
\end{tabular}

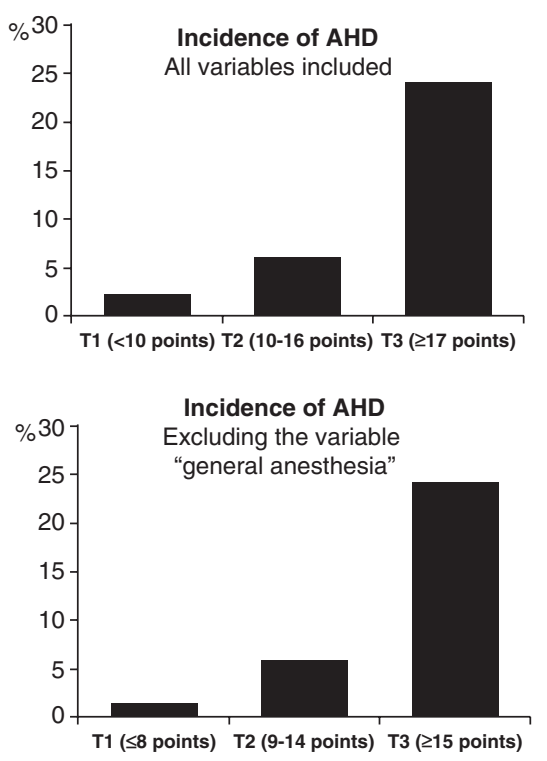

Fig. 10.1 Schematic representation of the PAINESD risk score to predict acute hemodynamic decompensation (AHD) during catheter ablation of ventricular tachycardia in patients with structural heart disease (Reproduced with permission from Santangeli et al. [73]) 
mostly benefit by advanced HF management and prophylactic implantation of a MHS device to reduce the risk of AHD and improve post-procedural outcomes.

\subsubsection{Characteristics of the Arrhythmogenic Substrate and Its Impact on Catheter Ablation Approach}

The electrophysiologic substrate of sustained VT in the setting of structural heart disease is usually represented by scar-related reentry, and the destruction of this substrate can potentially prevent VT (Fig. 10.2). The EAM substrate typically involves the basal perivalvular region of the LV and the interventricular septum with a high prevalence of midmyocardial or subepicardial substrates. Two typical scar patterns (anteroseptal and inferolateral) are found in up to $90 \%$ of patients with DCM and VT [66, 76]. Two VT morphologies are usually seen in presence of anteroseptal substrate: RBBB with inferior axis and positive concordance throughout the precordial leads or LBBB with inferior axis and early $(\leq \mathrm{V} 3)$ precordial transition (Figs. 10.3 and 10.4) [76]. Occasionally, VT arising from the septum may also present a characteristic precordial transition pattern break in V2 with a predominant $\mathrm{R}$ wave in V1 and V3 but an abrupt loss of the R wave in lead V2 due to an exit close to the anterior interventricular sulcus (opposite to lead V2) [66, 77]. A predominant inferolateral substrate can instead be identified in about half of the

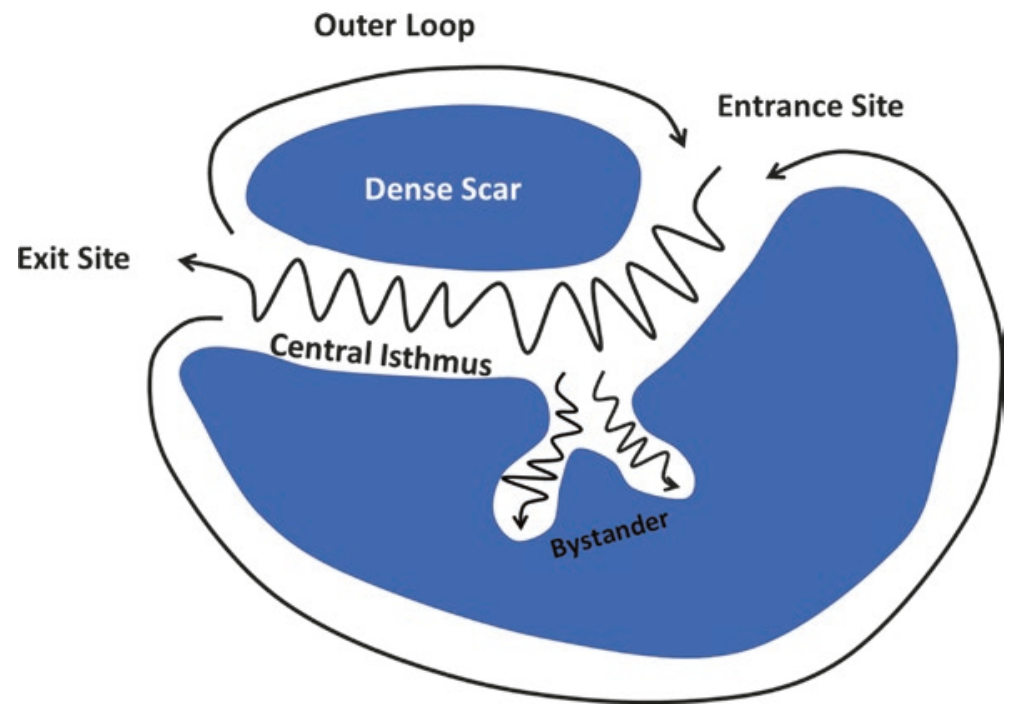

Fig. 10.2 Classic figure-of-eight reentry circuit as described by Stevenson et al. [75]. Blue regions represent areas of dense scar not excitable during tachycardia. The activation wave front propagates around two lines of conduction block sharing a central common isthmus. Bystander pathways can be attached to any point in the circuit and represent areas of tissue activated by the wave front but not playing an active role in the reentrant circuit 

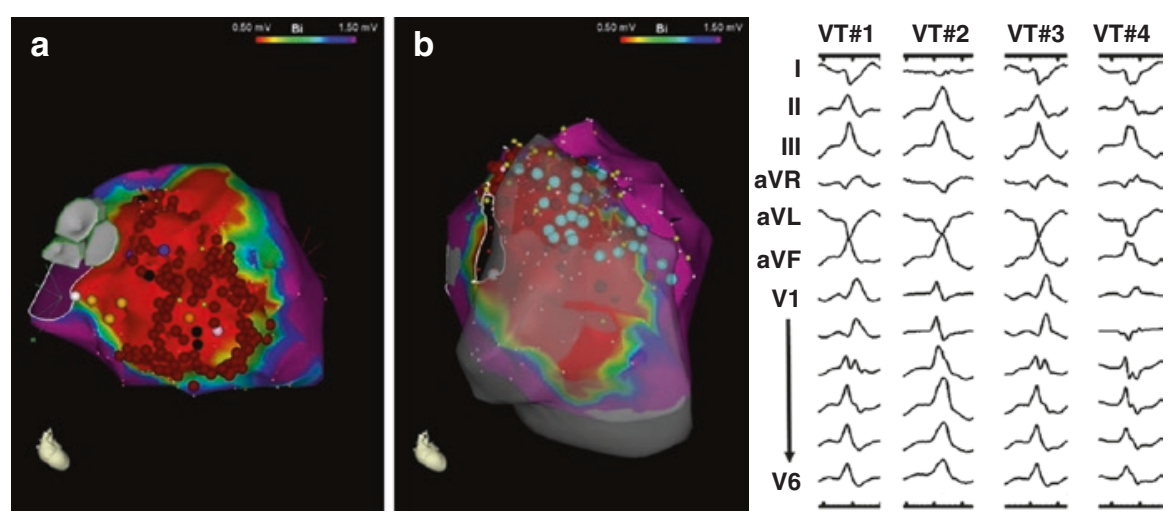

Fig. 10.3 Endocardial bipolar electroanatomic maps of a patient with multiple ventricular tachycardias (VT) arising from the interventricular septum who underwent extensive ablation from both the left ventricular (a, red dots) and right ventricular (b, light blue overlaid on LV septum) side of the septum

patients, and, in the majority of them (about 60\%), the critical VT sites are located on the epicardium. These patients typically present VTs of RBBB morphology with right superior axis and late ( $\geq$ V5) precordial transition (Fig. 10.5) [76]. The distinction between these two patterns is of great clinical value in terms of both procedural planning and outcomes. In patients with a predominant anteroseptal substrate, an epicardial approach is largely unnecessary, and the complex local anatomy (i.e., proximity to coronary vessels, presence of epicardial fat) usually limits the possibility to perform CA. Conversely, an epicardial approach is often required to achieve VT control in patients with a predominant inferolateral pattern. Even if epicardial coronary vessels and the phrenic nerve may obstacle epicardial CA in patients with inferolateral substrate, these patients typically have a more favorable outcome $(75 \%$ vs. 25\% VT-free survival at 1.5-year follow-up) and a lower need for redo procedures (7\% vs. 59\%) compared to patients with anteroseptal substrate [69]. In patients with septal VTs, the intramural location of the substrate can be difficult to address and may require sequential LV and right ventricular (RV) CA as well as the use of high RF energy potentially leading to collateral injury of the conduction system. A series of different approaches like bipolar RF ablation, high-intensity focused ultrasound, retractable needle ablation, and intracoronary ethanol ablation have been described to overcome the aforementioned limits, but none of them is currently available in routine clinical practice.

A variety of criteria can be used to address the need for epicardial mapping/ablation: (1) a 12-lead ECG of the VT suggesting an epicardial origin; (2) evidence of epicardial substrate on imaging studies (i.e., magnetic resonance, intracardiac echocardiography); (3) a unipolar voltage abnormality $(<8.3 \mathrm{mV})$ in the presence of no or minimal bipolar $(<1.5 \mathrm{mV})$ abnormality; and finally, failure of endocardial ablation (either early VT recurrence or persistent inducibility of clinical VT). Epicardial ablation approach is usually associated with a higher incidence of complications; 


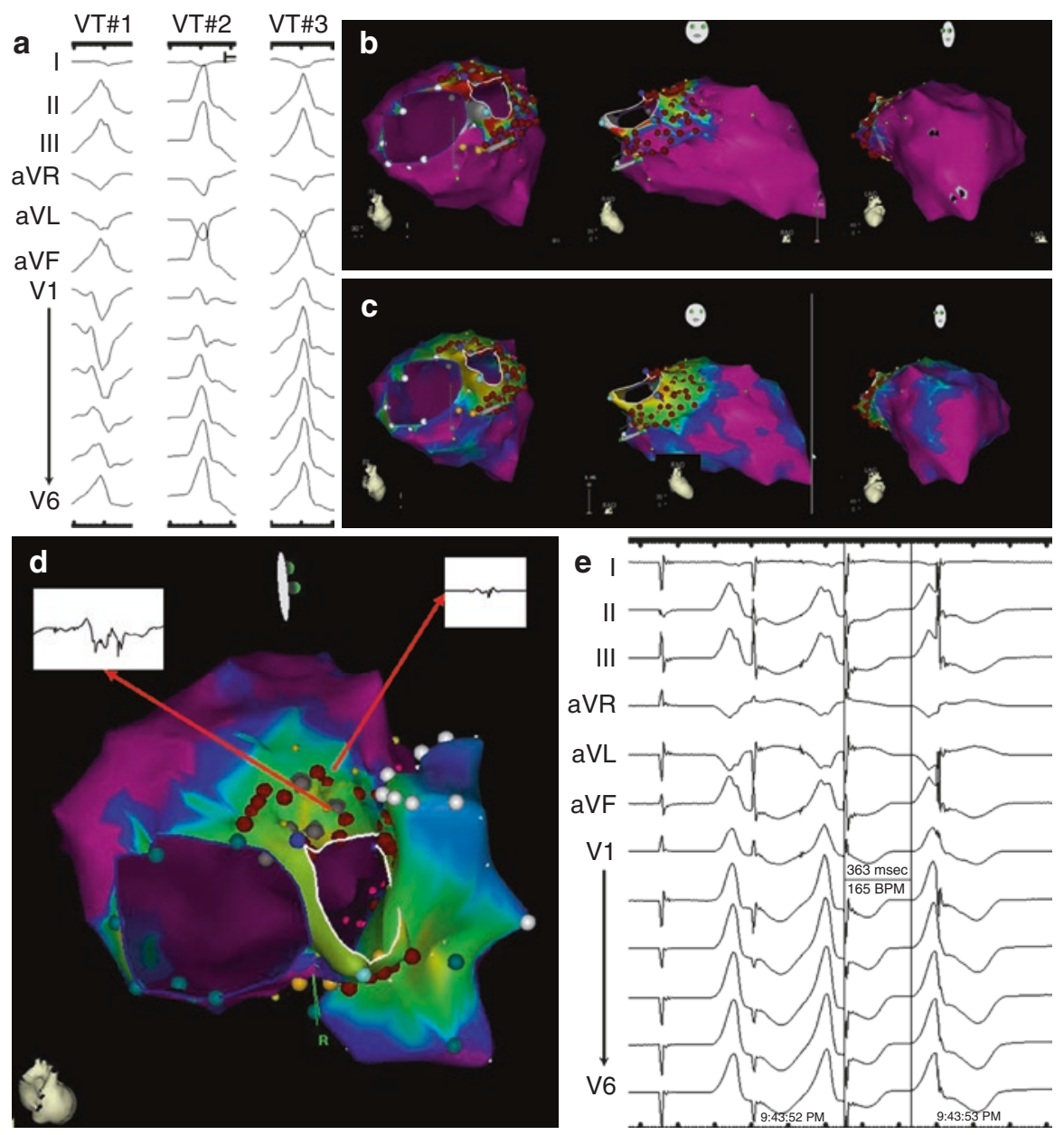

Fig. 10.4 Example of a 60-year-old lady with idiopathic dilated cardiomyopathy and left ventricular (LV) ejection fraction of $30 \%$ presenting with multiple ventricular tachycardias (VT) with both left bundle and right bundle branch morphology and inferior axis (a) consistent with an origin from the interventricular septum. Electroanatomic voltage mapping showed the presence of a small bipolar (b) and a larger unipolar (c) voltage abnormality involving the anterior septum. Extensive septal substrate ablation was performed from both the right and left side of the septum (b-d, red dots) targeting sites showing late potentials (d, red arrow) and long stim to QRS (e)

moreover, in a substantial proportion of cases (about 30\%), even if critical VT sites are found on the epicardial surface, CA cannot be safely performed due to close proximity of epicardial coronary vessels and left phrenic nerve or presence of epicardial fat. Several ECG features have been correlated to epicardial VT origin like wide QRS complexes (shortest RS complex in precordial leads $\geq 121 \mathrm{~ms}$ ), slow initial upstroke of the QRS complex "pseudo delta wave" $\geq 34 \mathrm{~ms}$, intrinsicoid deflection time $\geq 85 \mathrm{~ms}$, and maximum deflection index (shortest QRS onset to maximum precordial deflection/QRS duration) $\geq 0.55$ (Fig. 10.6) [78] 




Fig. 10.5 Example of endocardial (a) and epicardial (b and c) substrate modification in a patient with minimal endocardial substrate and typical inferolateral epicardial substrate. Black dots (b and c) indicate abnormal electrograms. Coronary angiography was performed to confirm safe distance of the ablation sites on the epicardium from the major coronary vessels (Reproduced with permission from Muser et al. [58])

\subsubsection{Role of ICD in DCM}

Since the beginning of this century, many studies evaluated the role of ICD for primary prevention of SD in patients with DCM. Despite a striking reduction of SD was evident in most cases, total mortality was not significantly reduced in all trials with the exception of the COMPANION study, comparing resynchronization therapy (CRT-P) only with resynchronization therapy + ICD (CRT-D).

Mortality rate in nonischemic heart disease is lower than in ischemic heart disease (5.4\% per year vs. $11.3 \%$ per year, respectively) [79], and this could partially explain why the absolute mortality reduction in patients with LV dysfunction of nonischemic origin is less evident [79]. In addition, nonischemic heart disease is not a synonymous of DCM: in unselected population with "nonischemic" HF, patients with other etiologies (hypertension, valvular heart disease, unrecognized myocarditis) have been included. The risk of death for other reasons (HF or noncardiac causes) can be not negligible, especially in older patients with other comorbidities, so the benefit of ICD could have been weakened by the competing risk due to other causes of death. Therefore, it is not surprising that in nonischemic patients, a significant effect on total mortality can be observed only in patients less likely to die for reasons different from SD (as young patients without severe heart failure symptoms) [25].

Nevertheless, the 2015 European Society of Cardiology (ESC) [27] Ventricular Arrhythmia Guidelines and the 2016 ESC Heart Failure Guidelines [80] give a 1B recommendation, while the $2017 \mathrm{AHA} / \mathrm{ACC} / \mathrm{HRS}$ Guidelines give a 1A recommendation for ICD implantation for primary prevention in patients with nonischemic etiology [28]. 


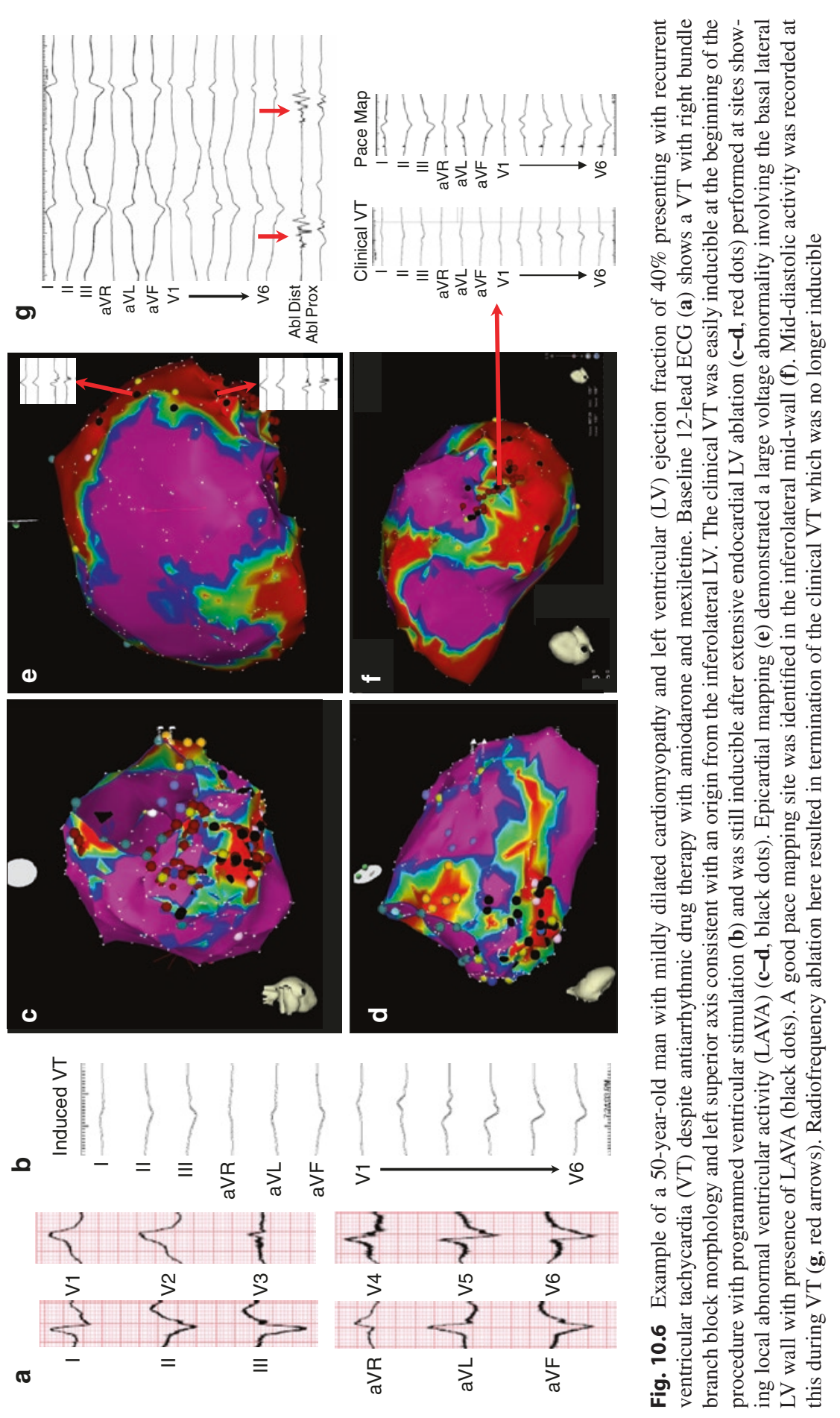




\section{References}

1. Towbin JA, Lorts A. Arrhythmias and dilated cardiomyopathy common pathogenetic pathways? J Am Coll Cardiol. 2011;57(21):2169-71.

2. McNair WP, Sinagra G, Taylor MR, Di Lenarda A, Ferguson DA, Salcedo EE, et al. SCN5A mutations associate with arrhythmic dilated cardiomyopathy and commonly localize to the voltage-sensing mechanism. J Am Coll Cardiol. 2011;57(21):2160-8.

3. Rapezzi C, Arbustini E, Caforio AL, Charron P, Gimeno-Blanes J, Heliö T, et al. Diagnostic work-up in cardiomyopathies: bridging the gap between clinical phenotypes and final diagnosis. A position statement from the ESC Working Group on Myocardial and Pericardial Diseases. Eur Heart J. 2013;34(19):1448-58.

4. Hershberger RE, Hedges DJ, Morales A. Dilated cardiomyopathy: the complexity of a diverse genetic architecture. Nat Rev Cardiol. 2013;10(9):531-47.

5. Arbustini E, Pilotto A, Repetto A, Grasso M, Negri A, Diegoli M, et al. Autosomal dominant dilated cardiomyopathy with atrioventricular block: a lamin A/C defect-related disease. J Am Coll Cardiol. 2002;39(6):981-90.

6. Taylor MR, Fain PR, Sinagra G, Robinson ML, Robertson AD, Carniel E, et al. Natural history of dilated cardiomyopathy due to lamin A/C gene mutations. J Am Coll Cardiol. 2003;41(5):771-80.

7. Brembilla-Perrot B, Alla F, Suty-Selton C, Huttin O, Blangy H, Sadoul N, et al. Nonischemic dilated cardiomyopathy: results of noninvasive and invasive evaluation in 310 patients and clinical significance of bundle branch block. Pacing Clin Electrophysiol. 2008;31(11):1383-90.

8. Aleksova A, Carriere C, Zecchin M, Barbati G, Vitrella G, Di Lenarda A, et al. New-onset left bundle branch block independently predicts long-term mortality in patients with idiopathic dilated cardiomyopathy: data from the Trieste Heart Muscle Disease Registry. Europace. 2014;16(10):1450-9.

9. Sekiguchi M, Hasegawa A, Hiroe M, Morimoto S, Nishikawa T. Inclusion of electric disturbance type cardiomyopathy in the classification of cardiomyopathy: a current review. J Cardiol. 2008;51(2):81-8.

10. Meune C, Van Berlo JH, Anselme F, Bonne G, Pinto YM, Duboc D. Primary prevention of sudden death in patients with lamin A/C gene mutations. N Engl J Med. 2006;354(2):209-10.

11. Aleksova A, Merlo M, Zecchin M, Sabbadini G, Barbati G, Vitrella G, et al. Impact of atrial fibrillation on outcome of patients with idiopathic dilated cardiomyopathy: data from the Heart Muscle Disease Registry of Trieste. Clin Med Res. 2010;8(3-4):142-9.

12. Spezzacatene A, Sinagra G, Merlo M, Barbati G, Graw SL, Brun F, et al. Arrhythmogenic phenotype in dilated cardiomyopathy: natural history and predictors of life-threatening arrhythmias. J Am Heart Assoc. 2015;4(10):e002149.

13. Holmes J, Kubo SH, Cody RJ, Kligfield P. Arrhythmias in ischemic and nonischemic dilated cardiomyopathy: prediction of mortality by ambulatory electrocardiography. Am J Cardiol. 1985;55(1):146-51.

14. Doval HC, Nul DR, Grancelli HO, Varini SD, Soifer S, Corrado G, et al. Nonsustained ventricular tachycardia in severe heart failure. Independent marker of increased mortality due to sudden death. GESICA-GEMA Investigators. Circulation. 1996;94(12):3198-203.

15. Meinertz T, Hofmann T, Kasper W, Treese N, Bechtold H, Stienen U, et al. Significance of ventricular arrhythmias in idiopathic dilated cardiomyopathy. Am J Cardiol. 1984;53(7):902-7.

16. Singh SN, Fisher SG, Carson PE, Fletcher RD. Prevalence and significance of nonsustained ventricular tachycardia in patients with premature ventricular contractions and heart failure treated with vasodilator therapy. Department of Veterans Affairs CHF STAT Investigators. J Am Coll Cardiol. 1998;32(4):942-7.

17. Grimm W, Christ M, Bach J, Müller HH, Maisch B. Noninvasive arrhythmia risk stratification in idiopathic dilated cardiomyopathy: results of the Marburg Cardiomyopathy Study. Circulation. 2003;108(23):2883-91. 
18. Zecchin M, Di Lenarda A, Gregori D, Merlo M, Pivetta A, Vitrella G, et al. Are nonsustained ventricular tachycardias predictive of major arrhythmias in patients with dilated cardiomyopathy on optimal medical treatment? Pacing Clin Electrophysiol. 2008;31(3):290-9.

19. Pogwizd SM, McKenzie JP, Cain ME. Mechanisms underlying spontaneous and induced ventricular arrhythmias in patients with idiopathic dilated cardiomyopathy. Circulation. 1998;98(22):2404-14.

20. Soejima K, Stevenson WG, Sapp JL, Selwyn AP, Couper G, Epstein LM. Endocardial and epicardial radiofrequency ablation of ventricular tachycardia associated with dilated cardiomyopathy: the importance of low-voltage scars. J Am Coll Cardiol. 2004;43(10):1834-42.

21. Streitner F, Kuschyk J, Dietrich C, Mahl E, Streitner I, Doesch C, et al. Comparison of ventricular tachyarrhythmia characteristics in patients with idiopathic dilated or ischemic cardiomyopathy and defibrillators implanted for primary prevention. Clin Cardiol. 2011;34(10):604-9.

22. Merlo M, Pivetta A, Pinamonti B, Stolfo D, Zecchin M, Barbati G, et al. Long-term prognostic impact of therapeutic strategies in patients with idiopathic dilated cardiomyopathy: changing mortality over the last 30 years. Eur J Heart Fail. 2014;16(3):317-24.

23. Strickberger SA, Hummel JD, Bartlett TG, Frumin HI, Schuger CD, Beau SL, et al. Amiodarone versus implantable cardioverter-defibrillator: randomized trial in patients with nonischemic dilated cardiomyopathy and asymptomatic nonsustained ventricular tachycardiaAMIOVIRT. J Am Coll Cardiol. 2003;41(10):1707-12.

24. Merlo M, Gentile P, Naso P, Sinagra G. The natural history of dilated cardiomyopathy: how has it changed? J Cardiovasc Med (Hagerstown). 2017;18(Suppl 1):e161-e5.

25. Køber L, Thune JJ, Nielsen JC, Haarbo J, Videbæk L, Korup E, et al. Defibrillator implantation in patients with nonischemic systolic heart failure. N Engl J Med. 2016;375(13):1221-30.

26. Zecchin M, Merlo M, Pivetta A, Barbati G, Lutman C, Gregori D, et al. How can optimization of medical treatment avoid unnecessary implantable cardioverter-defibrillator implantations in patients with idiopathic dilated cardiomyopathy presenting with "SCD-HeFT criteria?". Am J Cardiol. 2012;109(5):729-35.

27. Priori SG, Blomström-Lundqvist C. 2015 European Society of Cardiology Guidelines for the management of patients with ventricular arrhythmias and the prevention of sudden cardiac death summarized by co-chairs. Eur Heart J. 2015;36(41):2757-9.

28. Al-Khatib SM, Stevenson WG, Ackerman MJ, Bryant WJ, Callans DJ, Curtis AB, et al. 2017 AHA/ACC/HRS guideline for management of patients with ventricular arrhythmias and the prevention of sudden cardiac death: executive summary: a report of the American College of Cardiology/American Heart Association Task Force on Clinical Practice Guidelines and the Heart Rhythm Society. Circulation. 2017;15(10):e190-252.

29. Goldberger JJ, Subačius H, Patel T, Cunnane R, Kadish AH. Sudden cardiac death risk stratification in patients with nonischemic dilated cardiomyopathy. J Am Coll Cardiol. 2014;63(18):1879-89.

30. Disertori M, Rigoni M, Pace N, Casolo G, Masè M, Gonzini L, et al. Myocardial fibrosis assessment by LGE is a powerful predictor of ventricular tachyarrhythmias in ischemic and nonischemic LV dysfunction: a meta-analysis. JACC Cardiovasc Imaging. 2016;9(9):1046-55.

31. Arbustini E, Disertori M, Narula J. Primary prevention of sudden arrhythmic death in dilated cardiomyopathy current guidelines and risk stratification. JACC Heart Fail. 2017;5(1):39-43.

32. Bécane HM, Bonne G, Varnous S, Muchir A, Ortega V, Hammouda EH, et al. High incidence of sudden death with conduction system and myocardial disease due to lamins $\mathrm{A}$ and $\mathrm{C}$ gene mutation. Pacing Clin Electrophysiol. 2000;23(11 Pt 1):1661-6.

33. van Rijsingen IA, Arbustini E, Elliott PM, Mogensen J, Hermans-van Ast JF, van der Kooi AJ, et al. Risk factors for malignant ventricular arrhythmias in lamin a/c mutation carriers a European cohort study. J Am Coll Cardiol. 2012;59(5):493-500.

34. Phillips E, Levine SA. Auricular fibrillation without other evidence of heart disease; a cause of reversible heart failure. Am J Med. 1949;7(4):478-89.

35. Fenelon G, Wijns W, Andries E, Brugada P. Tachycardiomyopathy: mechanisms and clinical implications. Pacing Clin Electrophysiol. 1996;19(1):95-106. 
36. Gopinathannair R, Etheridge SP, Marchlinski FE, Spinale FG, Lakkireddy D, Olshansky B. Arrhythmia-induced cardiomyopathies: mechanisms, recognition, and management. J Am Coll Cardiol. 2015;66(15):1714-28.

37. Ellison KE, Stevenson WG, Sweeney MO, Epstein LM, Maisel WH. Management of arrhythmias in heart failure. Congest Heart Fail. 2003;9(2):91-9.

38. Baman TS, Lange DC, Ilg KJ, Gupta SK, Liu TY, Alguire C, et al. Relationship between burden of premature ventricular complexes and left ventricular function. Heart Rhythm. 2010;7(7):865-9.

39. Ban JE, Park HC, Park JS, Nagamoto Y, Choi JI, Lim HE, et al. Electrocardiographic and electrophysiological characteristics of premature ventricular complexes associated with left ventricular dysfunction in patients without structural heart disease. Europace. 2013;15(5):735-41.

40. Di Biase L, Mohanty P, Mohanty S, Santangeli P, Trivedi C, Lakkireddy D, et al. Ablation versus amiodarone for treatment of persistent atrial fibrillation in patients with congestive heart failure and an implanted device: results from the AATAC multicenter randomized trial. Circulation. 2016;133(17):1637-44.

41. Roy D, Talajic M, Nattel S, Wyse DG, Dorian P, Lee KL, et al. Rhythm control versus rate control for atrial fibrillation and heart failure. N Engl J Med. 2008;358(25):2667-77.

42. Van Gelder IC, Hagens VE, Bosker HA, Kingma JH, Kamp O, Kingma T, et al. A comparison of rate control and rhythm control in patients with recurrent persistent atrial fibrillation. $\mathrm{N}$ Engl J Med. 2002;347(23):1834-40.

43. Wyse DG, Waldo AL, DiMarco JP, Domanski MJ, Rosenberg Y, Schron EB, et al. A comparison of rate control and rhythm control in patients with atrial fibrillation. N Engl J Med. 2002;347(23):1825-33.

44. Pappone C, Augello G, Sala S, Gugliotta F, Vicedomini G, Gulletta S, et al. A randomized trial of circumferential pulmonary vein ablation versus antiarrhythmic drug therapy in paroxysmal atrial fibrillation: the APAF Study. J Am Coll Cardiol. 2006;48(11):2340-7.

45. Jais P, Cauchemez B, Macle L, Daoud E, Khairy P, Subbiah R, et al. Catheter ablation versus antiarrhythmic drugs for atrial fibrillation: the A4 study. Circulation. 2008;118(24):2498-505.

46. Kosiuk J, Nedios S, Darma A, Rolf S, Richter S, Arya A, et al. Impact of single atrial fibrillation catheter ablation on implantable cardioverter defibrillator therapies in patients with ischaemic and non-ischaemic cardiomyopathies. Europace. 2014;16(9):1322-6.

47. Marrouche NF, Brachmann J, Andresen D, Siebels J, Boersma L, Jordaens L, et al. Catheter ablation for atrial fibrillation with heart failure. N Engl J Med. 2018;378(5):417-27.

48. Bunch TJ, May HT, Bair TL, Jacobs V, Crandall BG, Cutler M, et al. Five-year outcomes of catheter ablation in patients with atrial fibrillation and left ventricular systolic dysfunction. $\mathrm{J}$ Cardiovasc Electrophysiol. 2015;26(4):363-70.

49. Santangeli P, Muser D, Maeda S, Filtz A, Zado ES, Frankel DS, et al. Comparative effectiveness of antiarrhythmic drugs and catheter ablation for the prevention of recurrent ventricular tachycardia in patients with implantable cardioverter-defibrillators: a systematic review and meta-analysis of randomized controlled trials. Heart Rhythm. 2016;13(7):1552-9.

50. Sapp JL, Parkash R, Tang AS. Ventricular tachycardia ablation versus antiarrhythmic-drug escalation. N Engl J Med. 2016;375(15):1499-500.

51. Packer DL, Prutkin JM, Hellkamp AS, Mitchell LB, Bernstein RC, Wood F, et al. Impact of implantable cardioverter-defibrillator, amiodarone, and placebo on the mode of death in stable patients with heart failure: analysis from the sudden cardiac death in heart failure trial. Circulation. 2009;120(22):2170-6.

52. Saksena S, Slee A, Waldo AL, Freemantle N, Reynolds M, Rosenberg Y, et al. Cardiovascular outcomes in the AFFIRM Trial (Atrial Fibrillation Follow-Up Investigation of Rhythm Management). An assessment of individual antiarrhythmic drug therapies compared with rate control with propensity score-matched analyses. J Am Coll Cardiol. 2011;58(19):1975-85.

53. Connolly SJ, Dorian P, Roberts RS, Gent M, Bailin S, Fain ES, et al. Comparison of betablockers, amiodarone plus beta-blockers, or sotalol for prevention of shocks from implantable cardioverter defibrillators: the OPTIC Study: a randomized trial. JAMA. 2006;295(2):165-71. 
54. Pacifico A, Hohnloser SH, Williams JH, Tao B, Saksena S, Henry PD, et al. Prevention of implantable-defibrillator shocks by treatment with sotalol. d,l-Sotalol Implantable Cardioverter-Defibrillator Study Group. N Engl J Med. 1999;340(24):1855-62.

55. Kettering K, Mewis C, Dörnberger V, Vonthein R, Bosch RF, Kühlkamp V. Efficacy of metoprolol and sotalol in the prevention of recurrences of sustained ventricular tachyarrhythmias in patients with an implantable cardioverter defibrillator. Pacing Clin Electrophysiol. 2002;25(11):1571-6.

56. Investigators CASTC. Preliminary report: effect of encainide and flecainide on mortality in a randomized trial of arrhythmia suppression after myocardial infarction. N Engl J Med. 1989;321(6):406-12.

57. Gao D, Van Herendael H, Alshengeiti L, Dorian P, Mangat I, Korley V, et al. Mexiletine as an adjunctive therapy to amiodarone reduces the frequency of ventricular tachyarrhythmia events in patients with an implantable defibrillator. J Cardiovasc Pharmacol. 2013;62(2):199-204.

58. Muser D, Santangeli P, Castro SA, Pathak RK, Liang JJ, Hayashi T, et al. Long-term outcome after catheter ablation of ventricular tachycardia in patients with nonischemic dilated cardiomyopathy. Circ Arrhythm Electrophysiol. 2016;9(10). pii: e004328.

59. Tung R, Vaseghi M, Frankel DS, Vergara P, Di Biase L, Nagashima K, et al. Freedom from recurrent ventricular tachycardia after catheter ablation is associated with improved survival in patients with structural heart disease: an International VT Ablation Center Collaborative Group study. Heart Rhythm. 2015;12(9):1997-2007.

60. Muser D, Mendelson T, Fahed J, Liang JJ, Castro SA, Zado E, et al. Impact of timing of recurrence following catheter ablation of scar-related ventricular tachycardia on subsequent mortality. Pacing Clin Electrophysiol. 2017;40(9):1010-6.

61. Hsia HH, Callans DJ, Marchlinski FE. Characterization of endocardial electrophysiological substrate in patients with nonischemic cardiomyopathy and monomorphic ventricular tachycardia. Circulation. 2003;108(6):704-10.

62. Cano O, Hutchinson M, Lin D, Garcia F, Zado E, Bala R, et al. Electroanatomic substrate and ablation outcome for suspected epicardial ventricular tachycardia in left ventricular nonischemic cardiomyopathy. J Am Coll Cardiol. 2009;54(9):799-808.

63. Nakahara S, Tung R, Ramirez RJ, Michowitz Y, Vaseghi M, Buch E, et al. Characterization of the arrhythmogenic substrate in ischemic and nonischemic cardiomyopathy implications for catheter ablation of hemodynamically unstable ventricular tachycardia. J Am Coll Cardiol. 2010;55(21):2355-65.

64. Schmidt B, Chun KR, Baensch D, Antz M, Koektuerk B, Tilz RR, et al. Catheter ablation for ventricular tachycardia after failed endocardial ablation: epicardial substrate or inappropriate endocardial ablation? Heart Rhythm. 2010;7(12):1746-52.

65. Arya A, Bode K, Piorkowski C, Bollmann A, Sommer P, Gaspar T, et al. Catheter ablation of electrical storm due to monomorphic ventricular tachycardia in patients with nonischemic cardiomyopathy: acute results and its effect on long-term survival. Pacing Clin Electrophysiol. 2010;33(12):1504-9.

66. Haqqani HM, Tschabrunn CM, Tzou WS, Dixit S, Cooper JM, Riley MP, et al. Isolated septal substrate for ventricular tachycardia in nonischemic dilated cardiomyopathy: incidence, characterization, and implications. Heart Rhythm. 2011;8(8):1169-76.

67. Piers SR, Leong DP, van Huls van Taxis CF, Tayyebi M, Trines SA, Pijnappels DA, et al. Outcome of ventricular tachycardia ablation in patients with nonischemic cardiomyopathy: the impact of noninducibility. Circ Arrhythm Electrophysiol. 2013;6(3):513-21.

68. Dinov B, Fiedler L, Schönbauer R, Bollmann A, Rolf S, Piorkowski C, et al. Outcomes in catheter ablation of ventricular tachycardia in dilated nonischemic cardiomyopathy compared with ischemic cardiomyopathy. Circulation. 2014;129:728-36.

69. Oloriz T, Silberbauer J, Maccabelli G, Mizuno H, Baratto F, Kirubakaran S, et al. Catheter ablation of ventricular arrhythmia in nonischemic cardiomyopathy: anteroseptal versus inferolateral scar sub-types. Circ Arrhythm Electrophysiol. 2014;7(3):414-23.

70. Dinov B, Arya A, Schratter A, Schirripa V, Fiedler L, Sommer P, et al. Catheter ablation of ventricular tachycardia and mortality in patients with nonischemic dilated cardiomyopathy: 
can noninducibility after ablation be a predictor for reduced mortality? Circ Arrhythm Electrophysiol. 2015;8(3):598-605.

71. Yu R, Ma S, Tung R, Stevens S, Macias C, Bradfield J, et al. Catheter ablation of scar-based ventricular tachycardia: relationship of procedure duration to outcomes and hospital mortality. Heart Rhythm. 2015;12(1):86-94.

72. Gökoğlan Y, Mohanty S, Gianni C, Santangeli P, Trivedi C, Güneş MF, et al. Scar homogenization versus limited-substrate ablation in patients with nonischemic cardiomyopathy and ventricular tachycardia. J Am Coll Cardiol. 2016;68(18):1990-8.

73. Santangeli P, Muser D, Zado ES, Magnani S, Khetpal S, Hutchinson MD, et al. Acute hemodynamic decompensation during catheter ablation of scar-related ventricular tachycardia: incidence, predictors, and impact on mortality. Circ Arrhythm Electrophysiol. 2015;8(1):68-75.

74. Muser D, Liang JJ, Castro SA, Hayashi T, Enriquez A, Troutman GS, et al. Outcomes with prophylactic use of percutaneous left ventricular assist devices in high-risk patients undergoing catheter ablation of scar-related ventricular tachycardia: a propensity-matched analysis. Heart Rhythm. 2018;15(10):1500-6.

75. Stevenson WG, Khan H, Sager P, Saxon LA, Middlekauff HR, Natterson PD, et al. Identification of reentry circuit sites during catheter mapping and radiofrequency ablation of ventricular tachycardia late after myocardial infarction. Circulation. 1993;88(4 Pt 1):1647-70.

76. Piers SR, Tao Q, van Huls van Taxis CF, Schalij MJ, van der Geest RJ, Zeppenfeld K. Contrastenhanced MRI-derived scar patterns and associated ventricular tachycardias in nonischemic cardiomyopathy: implications for the ablation strategy. Circ Arrhythm Electrophysiol. 2013;6(5):875-83.

77. Hayashi T, Santangeli P, Pathak RK, Muser D, Liang JJ, Castro SA, et al. Outcomes of catheter ablation of idiopathic outflow tract ventricular arrhythmias with an $\mathrm{R}$ wave pattern break in lead V2: a distinct clinical entity. J Cardiovasc Electrophysiol. 2017;28(5):504-14.

78. Berruezo A, Mont L, Nava S, Chueca E, Bartholomay E, Brugada J. Electrocardiographic recognition of the epicardial origin of ventricular tachycardias. Circulation. 2004;109(15):1842-7.

79. Shun-Shin MJ, Zheng SL, Cole GD, Howard JP, Whinnett ZI, Francis DP. Implantable cardioverter defibrillators for primary prevention of death in left ventricular dysfunction with and without ischaemic heart disease: a meta-analysis of 8567 patients in the 11 trials. Eur Heart J. 2017;38(22):1738-46.

80. Ponikowski P, Voors AA, Anker SD, Bueno H, Cleland JGF, Coats AJS, et al. 2016 ESC Guidelines for the diagnosis and treatment of acute and chronic heart failure: The Task Force for the diagnosis and treatment of acute and chronic heart failure of the European Society of Cardiology (ESC) Developed with the special contribution of the Heart Failure Association (HFA) of the ESC. Eur Heart J. 2016;37(27):2129-200.

Open Access This chapter is licensed under the terms of the Creative Commons Attribution 4.0 International License (http://creativecommons.org/licenses/by/4.0/), which permits use, sharing, adaptation, distribution and reproduction in any medium or format, as long as you give appropriate credit to the original author(s) and the source, provide a link to the Creative Commons license and indicate if changes were made.

The images or other third party material in this chapter are included in the chapter's Creative Commons license, unless indicated otherwise in a credit line to the material. If material is not included in the chapter's Creative Commons license and your intended use is not permitted by statutory regulation or exceeds the permitted use, you will need to obtain permission directly from the copyright holder. 